controls, but brought little economic gain to the territory concerned. The labour force was small and at the end of the tax concession the industry may shut down leaving the environment considerably impoverished and polluted as a result of its activities. Nevertheless the viewpoint was expressed, but not shared by all delegates, that ecologists must be not only conservationists but also realists and that in the developing situation in the islands there are cases where economic gain must be overriding even though it results in environmental destruction.

The discharge of domestic wastes, and in particular from large hotels, is a major problem in the West Indies and is one which appears to have received scant attention. In many islands the beachlands are an important economic resource but have been badly degraded as a result of effluent discharge or seepage from the neighbouring cesspits. Spectacular illustrations of this were shown by Dr E. Towle of the Caribbean Conservation Association, US Virgin Islands, who also discussed the overall problem of waste disposal in small islands. He suggested that central disposal systems with piped sewer mains may be impracticable, and that alternative measures may have to be planned.

In the course of the discussions four principal points emerged in relation to coastal pollution in the West Indies.

(a) There is insufficient public awareness of the dangers of environmental pollution, whether from solid or liquid wastes and considerable publicity is needed. Delegates suggested that, on the basis of the pictures shown to them by Cerame-Vivas and Towle, it would be useful to prepare a documentary film on coastal pollution which could be used to draw the attention of planners and Government to the need for caution in siting industry or sewage disposal plants.

(b) In small islands it may be possible to arrange for centralized sewage disposal, and by means of holding tanks in outlying areas and conveyor trucks all domestic wastes can be accumulated in one place for treatment and disposal away from prime beachland.

(c) In the rapid progress of development in the islands planners often omitted to include design for effluent discharge from proposed development and consideration of this was left until the development had commenced, by which time it may be too late to include the best disposal scheme.

(d) Insufficient information is available on the rate of breakdown of sewage in tropical environments and there is need for more research in this field.
Department of Zoology,

University of the West Indies,

I. M. Goodbody

Kingston 7 ,

Jamaica, W.I.

\section{Mercury and Man}

The disturbing problem of environmental mercury contamination was the subject of a conference which drew 450 scientists from government, industry and universities to Michigan State University in September. They concluded that the study of mercury in the environment must take account of the chemical form in which the element is present, for this influences the availability, means of transport and toxicity of mercury. There should be greater emphasis on investigations of the mechanisms and rates of formation of alkyl mercury compounds in the environment, and their subsequent transport through food chains. There was a general plea for a more uniform method of reporting the consequences of mercury contamination. A speaker reviewing analytical methods for use with mercury pointed out that the principal sources of error arose from losses associated with the preparation of samples.

A discussion of the effects of mercury loadings on humans revealed that exposures to inorganic mercury which produce mild symptoms could be related to a concentration of 5 p.p.m. in the blood. It was agreed that more data were needed before it would be possible to define loadings with alkyl mercury compounds which caused no risk to humans. Epidemiological data suggested that it was safe to have between 10 and 20 p.p.m. of these compounds in the blood, but the safety of $20-65$ p.p.m. was less certain. Thus more careful epidemiological studies must be made, relating human health to loadings with alkyl mercury compounds. But even the validity of these assessments should be accepted with reserve in view of reports of possible genetic effects, as well as clear evidence that the foetus is susceptible to damage by concentrations which are not associated with harm to the maternal

School of Public Health, University of Michigan,

B. D. Dinman Ann Arbor, Michegan, Rolf Hartung USA. 